\title{
Aportes para análise das políticas de ações afirmativas na UFRGS
}

\author{
Gregório Durlo Grisa \\ Jaime José Zitkoski \\ Universidade Federal do Rio Grande do Sul
}

\section{Resumo}

O artigo desenvolve a categoria Cultura do Reconhecimento como aporte teórico para analisar as transformações produzidas pelas ações afirmativas nas universidades brasileiras. Realizaram-se revisão bibliográfica e observações participantes na UFRGS. O trabalho se apoia na noção de habitus de Pierre Bourdieu, na teoria do reconhecimento de Axel Honneth e na produção de Nancy Fraser acerca da paridade participativa. As ações afirmativas podem promover uma cultura do reconhecimento nas instituições? Conclui-se que foram dados os primeiros passos para a materialização da cultura do reconhecimento e, por outro lado, propõe-se um conjunto de ações para desenvolvê-la de forma mais plena.

Palavras chaves: ações afirmativas. Cultura do reconhecimento. Democratização. Paridade participativa. 


\section{Contributions to examine the policies of affirmative action in UFRGS}

\section{Abstract}

The article develops the Recognition of Culture category as theoretical framework to analyze the changes produced by affirmative action in Brazilian universities. There were literature review and participant observations UFRGS. The work is based on the notion of habitus of Pierre Bourdieu, in theory recognition of Axel Honneth and Nancy Fraser over production of participatory parity. Can affirmative action promote a culture of recognition at institutions? The conclusions point out that the first steps towards materializing a culture of recognition were taken and, at the same time, proposes a set of actions to develop it in a more comprehensive manner.

Keywords: affirmative action. Recognition of the culture. Democratization. Participatory parity.

\section{Aportes para analizar las políticas de acción afirmativa UFRGS}

\section{Resumen}

Este artículo desarrolla la categoría Cultura del Reconocimiento como aporte teórico para analizar las transformaciones producidas por las acciones afirmativas en las universidades brasileñas. Se realizaron actividades como revisión bibliográfica y observaciones participantes en la UFRGS. El trabajo se apoya en la noción de habitus de Pierre Bourdieu, en la teoría del reconocimiento de Axel Honneth y en la producción de Nancy Fraser acerca de la paridad participativa. ¿Las acciones afirmativas pueden promover una cultura del reconocimiento en las instituciones? Concluimos que los primeros pasos ya fueron dados para materializar la cultura del reconocimiento y que, por otra parte, también ha sido planteado un conjunto de acciones para desarrollarla plenamente.

Palabras clave: Acciones afirmativas. Cultura del reconocimiento. Democratización. Paridad participativa. 


\section{Apports pour analyser les politiques de discrimination positive à IUFRGS}

\section{Resumé}

Cet article présente une analyse des changements produits par les actions de discrimination positive dans les universités brésiliennes, en ayant comme apport théorique la catégorie de la Culture de la Reconnaissance. On a réalisé des révisions bibliographiques, ainsi que des observations participantes à l'UFRGS. Le travail se base sur la notion d'habitus de Pierre Bourdieu, sur la théorie de la reconnaissance d'Axel Honneth et sur les écrits de Nancy Fraser à propos de la "parité de participation". Les actions de discrimination positive peuvent-elles promouvoir une reconnaissance de la culture dans les institutions? On conclut que les premiers pas ont déjà été faits vers la matérialisation de la culture de la reconnaissance, et on propose, par ailleurs, un ensemble d'actions pour la développer pleinement.

Mots-clés: Discrimination positive. Culture de la reconnaissance. Démocratisation. Parité de participation.

\section{Introdução}

Cultura e reconhecimento, o que querem dizer esses termos enquanto possibilidades teóricas? E o que pode ser criado e desenvolvido na conjugação desses conceitos? A relação aqui proposta tem potencial para nos oferecer um tipo ideal (Weber, 2006) para um modus operandi institucional?

Apresente reflexão tem o intuito de conceber a categoria Cultura do Reconhecimento como um corpo de sentido único e relacional, todavia, iremos pensar primeiramente sobre cada um dos pólos da categoria a fim demostrar maior precisão teórica sobre o que concebemos por cultura e por reconhecimento.

Em um segundo momento, buscamos articular esses conceitos com as políticas de ações afirmativas nas universidades,mais especificamente na UFRGS, para dar corpo a uma categoria analítica. Em síntese, esse é percurso da discussão que desenvolvemos. 


\section{Qual a concepção de cultura?}

A noção de cultura, nas ciências sociais, é bastante polissêmica. Os usos e conceituações historicamente desenvolvidos na antropologia, na sociologia e na filosofia têm suas especificidades e trajetórias, histórico esse que muitos autores, como Eagleton (2003) e Bauman (2000), traçaram com propriedade. O conteúdo das representações sociais de cultura e sua identificação com grupos sociais em determinados períodos da história está trabalhado de forma didática também no livro "A noção de cultura nas ciências sociais", de Denys Cuche (1999).

Grandes intelectuais se debruçaram sobre o conceito de cultura e o colocaram no rol das noções chaves para se entender as sociedades humanas. Franz Boas, Émile Durkhein, Max Weber, Ruth Benedict, Maragaret Mead, Bronislaw Malinowski e Claude Lévi-Strauss são clássicos da antropologia e da sociologia que influenciam todo corpo teórico sobre cultura.

Podemos falar em cultura moderna, cultura de massas, culturas populares, cultura religiosa, cultura política e outras. Interessa-nos aqui tratar da noção de cultura como um conjunto de práticas sociais, conscientes ou não, pautadas em crenças, valores, costumes e esquemas interpretativos que se institucionalizam nas sociedades. Mais precisamente, falamos de uma cultura institucional, que envolve a cultura profissional (Caria, 2008), pois nosso fenômeno de estudo é a universidade.

A noção de cultura aqui se filia, em aproximação, à tradição sociológica legada por Pierre Bourdieu em seu conceito de habitus. Segundo o autor, o habitus é um sistema de disposições, modos de perceber, de sentir, de fazer, de refletir, que nos leva a agir de determinada forma em uma dada circunstância. Na clássica conceituação:

Os habitus são sistemas de disposições duráveis e transponíveis, estruturas predispostas a funcionar como estruturas estruturantes, isto é, funcionam como princípios geradores e organizadores de práticas e de representações que podem ser objetivamente adaptadas a seu objetivo sem supor que se tenham em mira conscientemente estes fins e o controle das operações necessárias para obtê-los. (Bourdieu, 1980, p. 88)

O autor entende que o habitus gera uma lógica, uma racionalidade prática, é adquirido mediante a interação social e, ao mesmo tempo, é o classificador e o organizador desta interação. É condicionante das nossas ações, mas também condicionado por elas.

Apesar do esforço dialético empreendido por Bourdieu ao desenvolver um conceito de habitus que designe algo estruturado pelo campo, mas também estruturante do mesmo, críticas como a de Bernard Lahire (1998) (in: Caria, 2008) apontam que, no conceito de habitus, pressupõe-se sempre uma prevalência do passado sobre o presente: a estrutura estruturada prevalece sobre a estruturante, porque o improviso tende a ser sempre a reprodução de uma relação de forças herdada e atualizada no 
presente. Entendemos que o peso conferido à estrutura e aos códigos consolidados já existentes, dado por Bourdieu, ainda se justifica quando nos deparamos com a realidade de instituições com sólida tradição como a universidade.

Importante salientar que o conceito de habitus, aqui reivindicado para dar suporte à noção de cultura, tem suas dimensões individuais e coletivas. Habitus também pode ser lido como o resultado da experiência biográfica individual, da experiência histórica coletiva e da interação entre essas experiências. Os agentes sociais, indivíduos ou grupos, incorporam um habitus gerador (disposições adquiridas pela experiência) que varia no tempo e no espaço (Cherques, 2006).

Bourdieu aponta que habitus é uma capacidade infinita de gerar produtospensamentos, percepções, expressões e ações cujos limites são definidos pelas condições históricas e sociais situadas na sua produção. A liberdade condicional que o habitus fornece é tão distante da criação de novidade imprevisível como é de simples reprodução mecânica do condicionamento inicial. Ou seja, estamos falando tanto de uma construção social herdada como de uma autoconstrução constante, mas que sua regularidade exige tempo para ser tocada, pois pensar em inserir um elemento no habitus de modo instantâneo é tão ingênuo como crer que os seres humanos o reproduzem mecanicamente no seu cotidiano.

A cultura de uma instituição tem como base o habitus, esse tem existência em um campo, que não é um recorte espacial fixo, mas o cenário físico e simbólico em que o habitus é vivido e as relações de poder ocorrem. Por definição, o campo tem propriedades universais, isto é, presentes em todos os campos e, também, características próprias. As propriedades de um campo, além do habitus específico, são a estrutura, a opinião consensual, as representações aceitas, as leis que o regem e que regulam a luta pela dominação do campo (Cherques, 2006).

A vida acadêmica tem seu habitus, o meio acadêmico pode ser concebido como um campo, os pesquisadores (docentes) possuem uma cultura profissional específica. É nesse ambiente que nosso desafio teórico tem morada. Estamos cientes de que desenvolver ou não uma cultura do reconhecimento em uma instituição do ponto de vista objetivo, isto é, transformar em realidade um conjunto de práticas, esperanças e juízos é bem mais difícil do que engendrar um conceito, mas a reflexão pode ser semente nesse intento.

Quando estamos inseridos em um campo experimentando seu habitus, temos grandes dificuldades de compreendê-lo, pois cristalizamos seus valores a ponto de vislumbrarmos possibilidades restritas de mudanças ou rupturas. Assim como temos de ter vigilância epistemológica ao fazer uma pesquisa, é importante ficar atento a esses limites.

O meio acadêmico, como campo particular, tem um conjunto de códigos específicos, que demandam daqueles que desejam participar do seu meio, uma imersão nesse 
universo. Como nos ensina Cherques (2006, p. 40) com base em Bourdieu.

O direito de entrada no campo é dado pelo reconhecimento dos seus valores fundamentais, pelo conhecimento das regras do jogo, isto é, da história do campo e pela posse do capital específico. Os agentes aceitam os pressupostos cognitivos e valorativos do campo ao qual pertencem. Cada campo tem um sistema de filtragem diferente: um agente dominante em um campo pode não o ser em outro. A admissão no campo requer: a posse de diferentes formas de capital, o cacife (enjeux) na quantidade e qualidade do que conta na disputa interna e que constitui a finalidade, o propósito, do jogo específico; e as disposições, inclinações e aprendizados, que conformam o habitus do campo.

Os agentes no campo, diante da implantação de novas políticas públicas, passam a conviver com novos elementos nos seu habitus e, no caso das ações afirmativas na universidade, com novos atores no campo. Ocorre aí uma lenta adaptação que se vislumbra na relação dialética entre aquilo que o campo e o habitus imputam ao novo e aquilo que esse traz de diferente.

O campo acadêmico brasileiro criou um habitus com dinâmicas sofisticadas de inibição, por exemplo,ao discurso sobre o conflito racial. Portanto, o simples convívio com pessoas negras que, na última década, passou a ser a realidade dos acadêmicos com as ações afirmativas, já é um fator relevante, visto que as relações pessoais dos agentes é bastante circundada por relações profissionais.

Essa noção de cultura institucional pautada no habitus e no campo é que embasa a primeira parte da categoria Cultura do Reconhecimento.

\section{Reconhecimento: as bases do conceito}

Reconhecimento é um conceito que ganhou relevo a partir do surgimento de diferentes formas de conflitos sociais experimentadas na segunda metade do século XX. Esse tema entrou na agenda do debate público e ganhou atenção de inúmeros teóricos das ciências humanas, como Charles Taylor, Alain Touraine, Junger Habermas, Zygmunt Bauman. Relacionam-se com esses debates as clássicas reflexões de John Rawls sobre justiça e as contribuições dos autores identificados como pós-colonialistas, como Stuart Hall, Frantz Fanon, Albert Memmi e Edward Said. Todavia, para desenvolver nosso entendimento sobre reconhecimento, nos delimitamos a obra Nancy Fraser e de Axel Honnett.

Os conflitos sociais se dão em ambientes socialmente injustos, mas não se originam, necessariamente, de questões materiais. Ou seja, apesar de patologias sociais surgirem em contextos de pobreza material, elas nem sempre são desencadeadas por essa escassez, mas sim, pelo não reconhecimento de determinada característica dos grupos 
sociais ou de suas demandas.

Estudos recentes, como o de Fuhrmann (2013), que analisou as origens do fenômeno de rualização (ir morar na rua) infanto-juvenil no meio urbano, em Porto Alegre, e de Gratius e Valença (2011) sobre as explicações da violência em Caracas, na Venezuela, mostram a procedência da tese acima. Isto é, de que a deflagração de conflitos sociais se dá, em grande escala, pelas experiências de menosprezo, desrespeito, humilhação e não puramente por questões econômicas.

"A qualidade moral das relações sociais não pode ser mensurada exclusivamente em termos de uma distribuição justa ou equitativa de bens materiais" (Honnett,2007, p. 81). Com base nessa reflexão, tendo como pano de fundo empírico a luta secular do movimento negro no Brasil e o surgimento dos novos movimentos sociais identitários é que julgamos fecunda a interpretação de que modalidades distintas de negação de direitos e de desrespeitos produzem lutas organizadas que redesenham a noção de conflito social.

Experiências individuais de desrespeitos vividas por sujeitos em suas relações com o Estado ou com instâncias da sociedade civil, se compartilhadas em espaços solidários de debate político, podem se transformar em experiências coletivamente percebidas. Quando um círculo de indivíduos forma um grupo que tem em comum o problema de negação de reconhecimento, mesmo que essa negação se dê de maneira distinta, já se configura um novo modo de organização política.

$\mathrm{Na}$ medida em que os grupos se organizam e suas ideias passam a se inserir na sociedade, como pauta de reivindicação, ou na forma de conflito, elas constituem subculturas que apresentam outras maneiras de interpretar a realidade. Experiências de desrespeito que antes eram tomados como privadas passam a ter uma dimensão socializada e ser motivo mobilizador de luta por reconhecimento.

É na relação entre a experiência pessoal de negação de direitos e o vislumbrar em um grupo social a mudança dessa experiência que se organizam os coletivos e, por consequência, os conflitos que irão enfrentar.Essa é a direção conceitual que Honneth segue para compreender o conflito, ele afirma ao conceituar luta social:

Trata-se de um processo prático no qual experiências individuais de desrespeito são interpretadas como experiências cruciais típicas de um grupo inteiro, de forma que elas podem influir, como motivos diretores da ação, na exigência coletiva por relações ampliadas de reconhecimento. (Honneth, 2003, p. 257)

Porém, compreendemos que a luta por reconhecimento como um movimento contra desrespeitos, sejam eles de direitos ou de estima, deve abarcar a luta por redistribuição dos bens materiais da sociedade. A realidade que vivemos abriga tanto injustiças culturais, quanto injustiças econômicas. No cenário brasileiro, há uma íntima fusão entre os dois tipos de injustiça. 
A noção de reconhecimento, em sua apreciação inicial e incompleta em relação a como queremos concebê-la aqui, refere-se apenas a lutas sociais contra injustiças de carácter cultural ou identitário. Injustiças desse tipo se caracterizam por ações sociais de representação, interpretação e comunicação, seus exemplos incluem a dominação cultural, a invisibilização de determinados grupos sociais e o desrespeito (Fraser, 2006). Ser submetido a padrões de interpretação e valorativos de outras culturas, alheios aos seus, sofrer com o ocultamento de sua cultura nas práticas comunicativas e nas representações autorizadas e aceitas, bem como, ser desrespeitado rotineiramente por atitudes que desqualificam sua identidade e viver interações que produzem estereótipos são experiências individuas e coletivas que constituem as injustiças culturais.

Por outro lado, a redistribuição tem foco na luta contra as injustiças econômicas, essas são marcadas por questões estruturantes da sociedade capitalista, materializam-se através da exploração, da marginalização e da privação. As relações entre capital e trabalho são expostas como injustas à medida que a distribuição dos bens produzidos pelo ser humano é desigual e arbitrária.Ser explorado, vender sua força de trabalho, produzir algo de que não pode usufruir, ser obrigado a um trabalho que não deseja, em condições degradantes, ou não ter trabalho, bem como ser privado do acesso a condições materiais mínimas, são exemplos objetivos de injustiças econômicas (Fraser, 2006).

Com base no binômio reconhecimento-redistribuição,podemos pensar em tentativas de corrigir desequilíbrios sociais tanto sem abalar os alicerces da organização socioeconômica, como os modificando significativamente. Fraser (2006, p. 237) sugere a ideia de remédios:

Por remédios afirmativos para a injustiça, entendo os remédios voltados para corrigir efeitos desiguais de arranjos sociais sem abalar a estrutura subjacente que os engendra. Por remédios transformativos, em contraste, entendo os remédios voltados para corrigir efeitos desiguais precisamente por meio da remodelação da estrutura gerativa subjacente.

Portanto, podemos ter remédios afirmativos e remédios transformativos tanto para combater injustiças culturais como para combater injustiças econômicas. Diferente da linearidade com que a dicotomia reforma-revolução foi tratada em outros tempos históricos, aqui se pretende substituir maniqueísmo entre mudança gradual ou mudança total, por uma combinação de "remédios" que contemple a heterogeneidade do movimento do real.

Portanto, a ideia é ter, no conceito de reconhecimento, um conjunto combinado que responda à necessidade histórica dos grupos sociais que hoje lutam contra injustiças de variados tipos, que se expressam em múltiplas dimensões. Essa compreensão de reconhecimento nos permite compreender as ações afirmativas como políticas tanto redistributivas como de reconhecimento. 


\section{Reconhecimento como paridade participativa}

Podemos afirmar que reconhecimento e redistribuição são conceitos que possibilitam um conjunto de avanços do ponto de vista teórico, auxiliam-nos a fugir tanto do determinismo econômico, bem como, de certo modismo culturalista. Amalgamados, esses conceitos dão à luz ao conceito de reconhecimento no qual queremos nos apoiar ao desenvolver a categoria cultura do reconhecimento.

Temos pela frente uma nova tarefa intelectual e prática: desenvolver uma teoria crítica do reconhecimento, que identifique e assuma a defesa somente daquelas versões da política cultural da diferença que possam ser combinadas coerentemente com a política social da igualdade. Ao formular esse projeto, assumo que a justiça hoje exige tanto redistribuição como reconhecimento. E proponho examinar a relação entre eles. Isso significa, em parte, pensar em como conceituar reconhecimento cultural e igualdade social de forma a que sustentem um ao outro, ao invés de se aniquilarem. (Fraser, 2006, p. 231)

Essa passagem marca um desafio que a autora se fez e que encontra o encaminhamento mais definitivo no artigo Reconhecimento sem ética? em que Fraser amadurece sua crítica a Honneth e desenvolve sua proposta mais didaticamente. Basicamente, a autora, no caminho do que já vem sendo refletido, propõe a construção de um modelo teórico abrangente que tenha a redistribuição e o reconhecimento como dimensões irredutíveis conforme a realidade exige.

Para tal, Fraser defende que o reconhecimento tem de ser vinculado à noção de justiça e analisado como uma questão de status social ao invés do modelo de identidade cultural que prioriza reivindicações de exclusivismo em detrimento de reivindicações de superação de subordinações injustas (Fraser, 2007). Assim, questões subjetivas e individuais dariam espaço para demandas coletivas de transformações das culturas institucionais, ou seja, ao romper com o modelo de reconhecimento ligado à identidade, Fraser prioriza não mais elementos da estrutura psíquica dos indivíduos, mas sim, a interação social e as instituições.

O avanço de Fraser toma contorno quando ela desenvolve, dentro da concepção de justiça, a norma comum da paridade participativa.

As reivindicações por reconhecimento, bem como por redistribuição, devem atender anseios de colocar os grupos sociais em paridade para participar da vida social, seja em aspectos culturais ou econômicos. Tanto as condições objetivas, quanto as subjetivas são necessárias para a paridade participativa.

Uma inovação dessa proposta é notada quando Fraser se questiona se todas as reivindicações por reconhecimento e redistribuição são justas. Todas devem ser atendidas pelas comunidades e sociedades? Segundo a autora, a noção de paridade 
participativa deve servir de critério de avaliação para essas questões.

Os titulares das reivindicações por reconhecimento, por exemplo, precisam justificar suas demandas, provar que elas são necessárias e que, sem elas, estão impedidos de participar em condições de igualdade em relação aos demais. "Apenas aquelas reivindicações que promovem a paridade de participação são moralmente justificadas" (Fraser, 2007, p. 122).

A crítica a Honneth é feita quando Fraser desloca o reconhecimento da questão da autorrealização ou autoestima e o trata como uma demanda por justiça. Isso atribui ao reconhecimento um caráter moral de construção de códigos políticos coletivos e não mais o deixa vinculado a uma noção ética individual de realização de anseios de personalidade.

Nem toda demanda por promoção de autoestima representa promoção de justiça, esse raciocínio é ilustrado no seguinte exemplo: um grupo social racista reivindica ser reconhecido diante de todos por esse seu pensamento intolerante, isso iria promover a autoestima desse grupo, mas não se configura em uma promoção de justiça, pelo contrário, fere a lógica da paridade participativa descrita acima.

Nessa esteira, podemos dizer que nem toda autoestima promovida oferece um padrão de justificação para demandas de reconhecimento, ou seja, nem sempre quando se fortalece determinada identidade ou se promove a autoestima de alguns grupos, promove-se justiça social. Portanto, conceber o reconhecimento no modelo status ${ }^{1}$, relacioná-lo com aspectos morais e ter como critério avaliativo, dentro de uma concepção ampliada de justiça, a paridade participativa é "desinstitucionalizar padrões de valoração cultural que impedem a paridade de participação e substituílos por padrões que a promovam" (Fraser, 2007, p. 109,).

Conceber a dimensão do reconhecimento, nessa perspectiva, coaduna-se com as políticas de ação afirmativa por meio de cotas nas universidades. Quando se amplia a noção de justiça para que reconhecimento e redistribuição coexistam, assume-se que os eixos da injustiça social são simultaneamente culturais e socioeconômicos.

Fraser (2007) aponta que é necessário criarmos remédios que "desinstitucionalizem" o padrão de valores culturais que provocam o não reconhecimento, má distribuição ou empecilho para atingir maior paridade participativa na política, por exemplo. Essa é uma perspectiva interessante quando pensamos em instituições como as universidades tradicionais. Importante frisar que essa desinstitucionalização não significa somente a aceitação dos diferentes grupos sociais, o que seria uma vanglorização aparente da diferença.

Honneth (2003) trabalha com a ideia de que o reconhecimento seria uma forma de luta contra injustiças e por distribuição que se diferencia da luta de classes

1 Modelo minuciosamente explicado em Fraser, p. 108, 2007. 
homogeneamente concebida, mas que contempla aspectos de distribuição de renda, oportunidades e tensionamento de hierarquias sociais. A utilização de ambos os elementos semânticos, reconhecimento e redistribuição, trazidos pelos autores, tem o objetivo de aproveitar o que de relevante cada teoria tem para estudar o fenômeno pesquisado.

As ações afirmativas, nas universidades, foram políticas que requisitaram o autorreconhecimento dos sujeitos negros, sua identificação para superar injustiças sociais. Neste caso, trata-se de um reconhecimento positivo, de valorização da estética, da cultura e da história da população negra. Somando a histórica luta do movimento negro e a politização da pauta, esses elementos foram dando base reivindicatória e criando demanda para a implantação de políticas afirmativas.

A valorização cultural de identidades que, no passado, foram desprestigiadas e degradadas é um fenômeno repleto de vicissitudes, ao mesmo tempo em que faz da diferença, antes estigmatizada, agora um motivo de orgulho e de evolução de autoestima, mas pode se constituir, se mal conduzido, em certo exclusivismo culturalista. Esse pode reproduzir internamente, nos grupos demandantes, lógicas hierarquizantes de grupos dominantes da sociedade em que a luta está inserida, correndo o risco de não tocar no cerne do problema da exclusão e das desigualdades materiais.

Em outras palavras, nenhuma valorização de identidade está alheia aos padrões valorativos da sociedade como um todo, isto é, a lógica e os critérios para se conceber uma identidade positiva em determinada sociedade tende a obedecer a padrões hierarquizados pelos "bem-sucedidos", pela elite dessa sociedade, mesmo que a identidade em tela seja a de grupos sociais excluídos. O reconhecimento, enquanto conceito, não pode se reduzir a uma pretensa aceitação de culturas discriminadas historicamente e nem servir de álibi para que algumas lutas se transformem em meros embates sobre identidade e pela marcação da diferença.

Por isso, as ações afirmativas devem ser geridas com os olhos direcionados ao reconhecimento e à redistribuição, tendo claro que, nesse caso, houve a premência do autorreconhecimento. Os sujeitos históricos, imbuídos de consciência de sua condição específica e organizados, foram fundamentais para a confecção e implantação de políticas de intervenção que mudam suas possibilidades de acesso ao mais alto grau de escolaridade. Tendo a auto declaração como critério exigido para o acesso às ações afirmativas, o autorreconhecimento simbólico e político é condição para o estabelecimento e o êxito dessas políticas.

Concordamos com Féres Jr. (2002, p.571) que "o reconhecimento, como forma positiva, deve ser o produto do engajamento concreto das pessoas na política e não um valor a ser fixado através da especulação teórica". Com isso, não estamos dizendo que, para promover processos de mudanças sociais ou desenvolver políticas públicas de intervenção que preveem reconhecimento e/ou redistribuição, seja imperativo o 
autorreconhecimento de sujeitos e grupos sociais envolvidos.

Todavia, parece claro que, quando os sujeitos possuem autoconsciência, há uma substância mais densa na luta dos movimentos sociais, que mais se fortalecem quanto mais se autorreconhecem e partilham de diagnósticos da realidade mais refinados. Um dos grandes papéis das lutas por reconhecimento é o de mudar as representações sociais vigentes na sociedade, trazer à tona um debate que, ou se apresenta indigesto, ou está em estágio germinal de amadurecimento no imaginário coletivo. Podemos usar, como exemplo, pautas como: aborto, descriminalização das drogas, democratização da mídia, luta por moradia e pela terra, direitos dos homossexuais e outros.

A exigência de autorreconhecimento, no caso das políticas afirmativas, recheia o fenômeno, deixa-o mais completo, pois ambas as partes, sujeito e coletivos negros e o Estado promotor estão se desafiando e conduzindo o processo conscientemente. Os gestores públicos se depararam com a necessidade de desenvolver mecanismo para combater desigualdades e, com isso, a classe política e acadêmica teve de revisitar sua noção de justiça, perceber as falhas e limites dessa visão.

A disputa teórica que se trava na ciência política entre os defensores do reconhecimento e os adeptos da redistribuição tem sido fonte de energia para a lapidação de um conceito complementar que dê cobertura à multiplicidade de dimensões do movimento real. Essa disputa tem resultado em aproximações calcadas nos contextos políticos de diferentes regiões do mundo.

Entretanto, como já dito, não pensamos que se deve permanecer no estágio de defesa de um ou outro conceito, à luz dos avanços existentes e com a intenção de aproveitar o melhor de cada lado, pensamos ser viável identificar, nas políticas afirmativas, no que elas colocam em jogo, um fenômeno rico para consubstanciar as duas dimensões sociológicas, reconhecimento e redistribuição.

Nesse caso, tendo em conta esses aspectos bidimensionais é que incluímos, na ceara do conceito reconhecimento, os elementos e conteúdos da dimensão redistributiva. Caldear as duas essências abstratas em um ato de alargamento e oxigenação do conceito teórico crítico de reconhecimento é o que estamos propondo. Nosso desafio é revestir o conceito reconhecimento ao lhe acrescentar a dimensão redistributiva e a norma da paridade participativa. 


\section{Cultura do reconhecimento: um olhar sobre a realidade da UFRGS}

Conceber cultura do reconhecimento como categoria tem, em seu estágio de produção e justificação teórica, o momento mais inventivo e até certo ponto, artesanal. Porém, é ao adentrar no universo analítico que se poderá perceber sua capacidade. Para a categoria se candidatar a ser suporte hermenêutico tem de ser caracterizada e objetivada, isto é, tem de instaurar seus vínculos com a realidade empírica. O desafio do cientista social é objetivar a subjetividade, encontrar os laços entre a reflexão profunda e a materialidade dinâmica. Algumas das principais críticas que a Teoria do Reconhecimento de Honneth sofre se centra nas dificuldades de operacionalização teórico-metodológica do seu sistema conceitual em estudos empíricos.

Esse é um desafio infinito, tentativas de trazer dados da vida cotidiana que corroborem ou distorçam a perspectiva teórica é o movimento de aperfeiçoamento que o pesquisador social executa como ofício. Portanto, cabe passarmos a pensar a categoria cultura do reconhecimento em (de) uma instituição de modo mais prático.

Do ponto de vista da gestão da universidade, a aplicação da lei de ações afirmativas exigiu uma mudança institucional grande, a logística burocrática não se move para além da questão de sistemas de processamento de dados e fiscalização da documentação dos ingressantes. Parte do quadro pessoal técnico é mobilizada, no período das seleções, para executar tarefas de recepção, registro e organização. Com o passar dos anos, ações de gestão de formação dos funcionários passam a ser pensadas e a temática envolvendo as ações afirmativas, aos poucos, começa a fazer parte da vida da universidade e do radar da gestão.

Agentes centrais como os diretores de unidades acadêmicas, começam a ter que dar atenção não só ao novo perfil de estudante que passam a receber nos cursos, mas às novas exigências de integração e debates sobre diversidade com que são confrontados. A formação docente passa a ser cada vez mais reivindicada diante de novos desafios pedagógicos, e a gestão se defronta com a necessidade de aumentar a elasticidade de políticas de assistência estudantil.

Isso somado às reivindicações dos movimentos sociais negros, dos estudantes e de grupos políticos internos passa a formar um corpo de tensionamentos positivos para a vida da universidade. A democratização das instâncias burocráticas e dos órgãos deliberativos, por exemplo, passa a ser uma bandeira que ganha eco dentro de parcela do quadro docente e técnico da universidade. Todas essas ações concretas representam passos embrionários para materialização de uma cultura do reconhecimento. 
Uma cultura institucional, apesar de se constituir cotidianamente, no seu habitus, é uma engrenagem de lenta mobilidade. A redemocratização formal do Brasil, as disputas políticas e sociais contínuas da sociedade que adentram o século XXI com força são ingredientes que possibilitaram alguns avanços no seio acadêmico, entre eles, a adoção de ações afirmativas.

Carvalho (2006, p. 88), professor e antropólogo, leciona sobre tal política:

A implementação recente de um sistema de cotas para estudantes negros no ensino superior é um fenômeno que rompe radicalmente com a lógica de funcionamento do mundo acadêmico brasileiro desde a sua origem no início do século passado. Por um lado, as cotas estão provocando um reposicionamento concreto das relações raciais no nosso meio acadêmico, começando pelo universo discente da graduação, porém com potencial para estender-se à pós-graduação, ao corpo docente e aos pesquisadores.

Nesse mesmo artigo, o autor argumenta que, no Brasil, a história do ensino superior é marcada por um confinamento racial do mundo acadêmico. Em um levantamento apresentado nesse trabalho, feito em grandes universidades do país, constatou-se que, em nenhuma delas, que são vistas como referências nacionais na pesquisa, havia $1 \%$ ou mais de professores negros no seu quadro docente. A UFRGS, segundo o autor, tinha 0,2\% de negros entre os docentes no início dos anos 2000.

Carvalho (2006) coloca em xeque as interpretações sobre as relações raciais no Brasil quando feitas por um meio acadêmico segregado, justifica esse questionamento ao lembrar que a noção de democracia racial, denunciada como mito por Florestan Fernandes (1965), e todas as teorias que negam o racismo estrutural brasileiro nasceram nesse contexto. Essa segregação racial do meio acadêmico nunca foi imposta por lei ou regra, no entanto, ocorre na materialidade, constituindo um campo e um habitus determinado.

Ao revés desse cenário, podemos pensar a categoria cultura do reconhecimento em uma universidade como uma metáfora que pode tencionar a capacidade da instituição de constantemente se democratizar em todos os seus aspectos. Ela está plenamente ligada à função social da universidade perante a multiplicidade de desafios que a sociedade a apresenta.

Cultura do reconhecimento também é um cobertor semântico com o qual podemos identificar o grau de qualidade das respostas que a universidade vem dando, do ponto de vista técnico, estrutural, político e científico, para essas demandas contemporâneas apresentadas. Identificar essa qualidade vai de encontro com os métodos mensuráveis que sustentam o conceito de excelência com base na meritocracia, isto é, a cultura do reconhecimento pode oferecer outros critérios para se atribuir a qualidade de uma instituição.

Avaliar, planejar e gerir são ações que podem ganhar outro horizonte, outra lógica 
para funcionar, não é ingenuamente assumido aqui, que o novo advêm de vontades individuais ou de grupos que desconsideram o instituído. Podemos dizer que a cultura do reconhecimento é uma substância a ser inserida no habitus para vislumbrar outro projeto ético de universidade, que traga outros princípios para execução do fazer acadêmico e problematize os instituídos que não correspondam com os preceitos que incluímos aqui no bojo do conceito de reconhecimento.

Uma universidade que tem no seio dos seus processos de funcionamento, um conjunto complexo de dinâmicas, não terá homogeneidade nem nas práticas instrumentais burocráticas, nem nas científicas pedagógicas. De alguma forma, uma cultura do reconhecimento, à medida que já ingressou na esteira do habitus, no exemplo da UFRGS, da instituição, ao mesmo tempo, ainda precisa reforçar esse ingresso. Isto é, é na constância e na insegurança das formatações específicas que, através das brechas das microrrelações, incluem-se novos elementos de reconhecimento.

Não há linearidade, nem coerência espaço-temporal nesse processo, enquanto, em alguns ambientes da instituição existem avanços pontuais, em outros, eles ainda estão para nascer e de um jeito distinto dos outros. As ações e atividades que atendam a uma cultura do reconhecimento são átomos em meios a um corpo maior. A massa total das instituições tem características imprecisas, mas que respondem, como vimos quando conceituamos cultura, a aspectos hegemônicos, frutos das relações de poder.

A inclusão de pautas progressistas nas mais variadas instâncias administrativas da universidade, os debates e as mudanças legislativas promovidos por essas pautas formam o corpo empírico da cultura do reconhecimento. A criação de novos cursos ligados às camadas populares (Educação do campo, Políticas públicas) e o fortalecimento de esferas administrativas que sejam representativas dos movimentos sociais, também caminham nessa direção.

A mudança dos critérios de correção das redações do vestibular na UFRGS, em 2011², a criação da Coordenadoria de Ações Afirmativas, em 2012, a criação da Escola de Desenvolvimento da UFRGS ${ }^{3}$, a criação de eventos anuais como os vários Salões de Extensão, Ações Afirmativas, de Ensino, de Pós-graduação, de Relações Internacionais, com temas inclusivos, são exemplos de mudanças institucionais orientadas para o desenvolvimento da cultura do reconhecimento.

Há outros exemplos, como a ampliação do número de pesquisas e de grupos de estudos ligados às pautas da população negra, dos indígenas, dos quilombolas, das mulheres, da população LGBT. Esses são movimentos concretos que se estabelecem

2 A referida mudança fez com que se passasse a corrigir redações de $4 x$ o número de vagas em cada modalidade de ingresso. Isso fez com que mais candidatos às cotas fossem aprovados, em especial os negros.

3 Que tem como objetivo geral promover a qualificação dos servidores através de um conjunto de atividades de aprendizagem e formação interdependentes, que permitam o desenvolvimento pessoal e profissional, principalmente, dos funcionários de perfil de baixa escolaridade ligados a trabalhos operacionais. 
e que preparam um ambiente mais aprazível de acolhimento e convivência para os alunos cotistas, quando comparado com o existente há cinco ou dez anos.

\section{Considerações finais}

Diante dos elementos expostos até aqui, entendemos que as ações afirmativas dirigidas à população negra nas universidades, ao provocarem desconfortos concretos em subjetividades até então anestesiadas pelos privilégios, ou pela alienação acerca do tema, constituem-se em ferramenta essencial para o desenvolvimento de uma cultura do reconhecimento, ainda em germinais patamares no meio acadêmico nacional.

A cultura do reconhecimento tem como motor fundamental, não o único, a implantação das ações afirmativas e só poderá lograr êxito, tornando-se um novo habitus da academia, à medida que essas políticas continuarem existindo e se aperfeiçoando.

Nossas observações indicam que as contradições e disputas pelo habitus ganharam outro estágio de qualidade com um mínimo equilíbrio nas forças dentro da gestão da universidade. Com a ascensão a cargos estratégicos de profissionais que compartilham da necessidade de desenvolver uma cultura do reconhecimento na universidade, tem-se uma mexida progressista na distribuição das peças no campo. Isso aconteceu na UFRGS, ainda que de forma modesta.

Por outro lado, as resistências a mudanças representadas por importantes setores da universidade, fazem com que a gestão lide de modo ponderado e, em alguns casos, receoso, deixando de encaminhar e propor modificações legais e estruturais. Os movimentos de estudantes, os sindicatos dos funcionários técnicos e um segmento sindical dos docentes com inspiração mais crítica encontram dificuldades de pontuar questões para o grande grupo da instituição. O debate da paridade, de concurso público para segurança universitária, o questionamento de alguns convênios da universidade não considerados estratégicos e adequados por esses grupos, não entram na pauta global da universidade com a intensidade que merecem.

Cabe dizer que a real vivência de uma cultura do reconhecimento pressupõe que a instituição cumpra com seu histórico papel de oferecer formação profissional, promover pesquisa e extensão e, no caso das cotas, conseguir diplomar os sujeitos dessa política em número, no mínimo, igual ao daqueles que ingressam pelo sistema universal.

Por estarmos compreendendo as ações afirmativas comopolíticas redistributivas de oportunidades, elas devem garantir o desenvolvimento formal de uma boa trajetória acadêmica para seus usuários, isso não será exequível sem: a qualificação da 
permanência, o combate à retenção, a contínua formação dos professores e técnicos em temática específica, um maior investimento em avaliação interna dos órgãos institucionais, a oferta de disciplinas obrigatórias nas licenciaturas e bacharelados que tratam das relações étnico-raciais, a ampliação dos espaços e mecanismos de integração dos alunos cotistas, enfim, sem um conjunto amplo de ações institucionais.

O conjunto de ações listado acima é, ao ser colocado em prática dentro das suas complexidades e possibilidades, ampla promoção da cultura do reconhecimento dentro da instituição. Portanto, esse guarda-chuva semântico e teórico que é a categoria de cultura do reconhecimento só poderá existir quando houver, em forma de processo, o transplante do que foi aqui conceituado para a realidade concreta, vivida e construída por sujeitos históricos determinados.

\section{Referências}

BAUMAN, Zigmund. Culture as Praxis. Londres, Sage, 2000.

BOURDIEU, Pierre. O poder simbólico. Rio de Janeiro: Bertrand Brasil, 2001. . Lê Sens Pratique. Paris: Minuit, 1980.

. The Logic of Practice. Stanford, CA: Stanford University Press, 1990.

. A economia das trocas simbólicas. São Paulo: Perspectiva, 1992.

. Razões práticas: sobre a teoria da ação. São Paulo: Papirus, 1996.

. Capital Cultural, Escuela y Espacio Social. México: Siglo Veinteuno, 1997.

CARIA, Telmo. O uso do conceito de cultura na investigação sobre profissões. Análise Social, vol.XLIII(4. $\left.{ }^{\circ}\right)$, pp. 749-773, 2008.

CARVALHO, José Jorge. O confinamento racial do mundo acadêmico brasileiro. REVISTA USP, São Paulo, n.68, pp. 88-103, dez/fev 2005-2006.

CHERQUES, Hermano Roberto. Pierre Bourdieu: a teoria na prática. RAP Rio de Janeiro 40(1): 27-55, Jan./Fev. 2006.

CUCHC, Denys. A noção de cultura nas ciências sociais. Bauru: EDUSC, 1999.

EAGLETON, Terry. A Ideia de Cultura. Lisboa, Temas \& Debates, 2003.

FERES JÚNIOR, João. Contribuição a uma Tipologia das Formas de Desrespeito: Para Além do Modelo Hegeliano-Republicano. DADOS - Revista de Ciências Sociais, Rio de Janeiro, Vol. 45, n²4, pp. 555 a 576, 2002. 
FERNANDES, Florestan. A Integração do Negro na Sociedade de Classes. São Paulo, Cia. Editora Nacional, 1965.

FRASER, Nancy.Da redistribuição ao reconhecimento? Dilemas da justiça na era pós-socialista. Cadernos de campo, São Paulo, n. 14/15, pp. 231-239, 2006.

Reconhecimento sem ética? Lua Nova, São Paulo, 70: 213-222, 2007.

FUHRMANN, Nadia Lucia.O primado do Reconhecimento sobre a redistribuição: a origem dos conflitos sociais a partir da teoria de Axel Honneth. Sociologias, Porto Alegre, ano 15, n 33, mai./ago, pp. 170-203, 2013.

GRATIUS, Susanne; VALENÇA, Marcelo. Violência Urbana em Caracas e no Riode Janeiro: respostas locais e europeias. Madri: FRIDE, 2011.

HONNETH, Axel. Luta por reconhecimento: a gramática moral dos conflitos sociais. Trad. de Luiz Repa. São Paulo: Ed. 34, 2003.

. Reconhecimento ou Redistribuição? A mudança de perspectivana ordem moral da sociedade. In: SOUZA, J.; MATTOS, P. (Orgs) Teoria Crítica no Século XXI. São Paulo: Annablume, 2007.

WEBER, Max. A objetividade do conhecimento nas ciências sociais. São Paulo: Ática, 2006.

Recebido em setembro de 2016.

Aceito em junho de 2017.

Gregório Durlo Grisa é Doutor em Educação (UFRGS) e Pós-Doutorando em Sociologia (UFRGS). Bolsista do CNPa de Pós-Doutorado Júnior. Membro do Grupo de Estudos sobre a Universidade (GEU). Email: grisagregorio@yahoo.com.br

Jaime José Zitkosk é Doutor em Educação, Professor da Faculdade de Educação da UFRGS e do Porgrama de Pós-Graduação em Educação da UFRGS. Membro do Grupo de Pesquisa Inovação e Avaliação na Universidade (INOVAVAL). Email: 00086365@ ufrgs.br 